\title{
Trends of the Global Hepatitis C Disease Burden: Strategies to Achieve Elimination
}

\author{
Nathalie Brunner', Philip Bruggmann ${ }^{1,2}$ \\ ${ }^{1}$ Swiss Hepatitis, Zurich, Switzerland; ${ }^{2}$ Arud Centre for Addiction Medicine, Zurich, Switzerland
}

Hepatitis $\mathrm{C}$ infection is responsible for high morbidity and mortality rates globally as well as for significant indirect costs. The disease burden caused by the hepatitis $\mathrm{C}$ virus ( $\mathrm{HCV}$ ) is comparable to the one caused by human immunodeficiency virus or tuberculosis. Today, simple detection methods, highly effective and easy to administer therapies and efficient preventative measures are available to combat hepatitis C. Nevertheless, in most countries around the world, the World Health Organization target of eliminating this infectious disease and its consequences by 2030 are not being met. Significant gaps in care for hepatitis $C$ sufferers still exist, the shortcomings ranging from education and treatment to aftercare. Hepatitis $\mathrm{C}$ infection was and still is not on the radar of most politicians and health authorities. National programmes and strategies to combat the disease exist or are being developed in many countries. However, for these to be implemented efficiently and successfully, clear political commitment, strong civil society actors, well-functioning public health structures and the relevant support from global donors are needed.

Key words: Hepatitis C, Policy, HIV, Awareness, Public health

\section{INTRODUCTION}

The hepatitis $\mathrm{C}$ virus (HCV) is a blood-borne virus. Major transmission routes are sharing injection and other drug-use paraphernalia, blood-contaminated needles as well as medical procedures and blood transfusions. Injecting drug use accounts for the majority of infections in high-income countries [1]. In low-income and middle-income countries, lack of sufficient sterile medical equipment and procedures, such as surgery, dialysis and dental care, are the dominant risk factors for $\mathrm{HCV}$ infection [2-4]. Sexual transmission is rare except for high-risk

Received: March 17, 2021 Accepted: June 10, 2021

Corresponding author: Philip Bruggmann

Arud Centre for Addiction Medicine, 31 Schützengasse, Zurich 8001,

Switzerland

E-mail: p.bruggmann@arud.ch

This is an Open Access article distributed under the terms of the Creative Commons Attribution Non-Commercial License (https://creativecommons.org/licenses/by$\mathrm{nc} / 4.0 /$ ) which permits unrestricted non-commercial use, distribution, and reproduction in any medium, provided the original work is properly cited. sexual practices among men who have sex with men (MSM) who are either human immunodeficiency virus (HIV) positive or on pre-exposure-prophylaxis for HIV [5]. HCV can also be transmitted vertically, although it is much less likely to be passed on from mother to child than hepatitis B. Insufficiently sterile applied tattoos and piercings can be another potential route of HCV transmission [6,7].

A hepatitis $C$ infection causes no specific symptoms. And because it is such a 'silent' infection, many people are not aware of their potentially life-threatening medical condition. People may suffer from non-specific symptoms like fatigue, abdominal pain, cognitive impairment or joint pain, which are often not associated with an underlying HCV infection. All of these symptoms and medical conditions are likely to improve significantly if not go away completely if HCV is treated successfully.

An antibody test is used to screen for HCV. To confirm an ongoing infection, a positive antibody test must be followed by a virus detection test, usually a polymerase chain reaction test. Whereas the rapid point-of-care HCV antibody test can be done 
quickly, the technology for a rapid, broadly available and affordable, decentralised virus detection test is still being developed [8].

Since the introduction of the highly effective direct-acting antivirals (DAAs) in 2014, hepatitis C can be cured in more than $90 \%$ of cases [9]. With the new-generation DAAs, the average length of treatment is 8-12 weeks, consisting of 1 tablet to 3 tablets taken once daily. Serious side effects are rare. In most countries where DAA therapy is available, the medication is expensive. However, generic versions of the DAA combinations are available, mainly in low-income and middle-income countries.

With the testing and treatment possibilities described above, the tools for eliminating this chronic viral infection do exist, but there remain serious gaps in the cascade of care, mainly in regions and settings with limited resources [10]. Overall, only a small minority of the affected population have profited from the highly effective DAA treatment so far [11].

In response to the mounting evidence about the massive impact that hepatitis $B$ and $C$ have on the global burden of disease (GBD), four years ago, the World Health Organization (WHO) launched its first Global Health Sector Strategy to fight viral hepatitis B and C. It aims to eliminate hepatitis as a public health threat by 2030 [12]. Simultaneously, the World Health Assembly urged its member states to establish and implement national hepatitis programmes [13].

This paper aims to provide a detailed account of the current disease burden of HCV and to outline the steps that now need to be taken for the national and regional strategies and programmes to achieve the goal of elimination.

\section{DISEASE BURDEN}

Globally, hepatitis C and its sequelae place a significant burden on public health, the healthcare system and the economy. An estimated 71 million people across the globe are living with chronic hepatitis C [14]. According to the WHO, 399000 individuals died in 2016 as a result of chronic viral hepatitis, mainly from liver cirrhosis and liver cancer [15]. Prevalence of hepatitis C worldwide varies from $0.5 \%$ to $2.5 \%$, with the highest prevalence in the Eastern Mediterranean and Europe. According to the WHO, there are about 1.75 million new infections per year globally, resulting in a global incidence of HCV of 23.7 cases per 100000 population [15].

Due to the slow progression of HCV-induced liver damage, these severe consequences are often not associated with longterm HCV infection. As a result, the disease is under-reported as a cause for morbidity and mortality all over the world [16]. Worldwide, the number of deaths caused by viral hepatitis $B$ and $C$ is on the rise, with mortality rates similar to HIV and higher than tuberculosis (TB) and malaria [16].

Extrahepatic manifestations of a chronic hepatitis $C$ infection contribute significantly to the burden of this disease [17]. Depression, chronic renal disease, type 2 diabetes and cardiovascular disease are the most common ones. One and a half million disability-adjusted life years per year are lost due to hepatitis-C-associated cardiovascular disease, mainly in lowincome and middle-income countries [18]. These extrahepatic manifestations create direct medical costs [19] and indirect costs due to diminished workplace productivity $[20,21]$. Besides facing long-term morbidity and possible premature death, individuals infected with HCV may suffer from reduced quality of life and be faced with indirect costs such as substantial financial loss [22].

\section{POLICY}

Although HCV and HIV share a similar disease burden, HCV has never received the same attention. It has always been overshadowed by HIV in terms of public awareness and attention, and available resources. The reasons are not only to be found in the medical sector but also in the socio-political context and when the epidemics emerged [23]. HCV was never top of the agenda for healthcare policy-makers and other stakeholders. It took the WHO until 2016 to launch its first Global Health Sector Strategy on Viral Hepatitis [12].

In medicine, it is an all too rare opportunity to eradicate a chronic viral infection. Nevertheless, most of the chronically HCV infected people stay untreated or even unaware of their condition. There are many obstacles to overcome in order to scale up treatment and prevent transmission of the virus in every sector of the health system and many challenges to be faced within the political and financial sector of each country.

The challenges and obstacles are all interconnected. To tackle them, cohesive strategic planning and an attentive approach is needed from the local to the international level. The continuum of care must include raising awareness of $\mathrm{HCV}$, increasing knowledge of the transmission routes, introducing affordable preventative measures, improving access to testing and treatment, providing reliable data and surveillance, and raising ad- 
equate funding for all these efforts. In addition to that, it takes good governance and accountability, research and monitoring as well as financial planning and proper funding to achieve a comprehensive policy.

\section{STRATEGY- LOCAL, NATIONAL, INTERNATIONAL}

In general, national and international strategies are effective tools to strengthen political will, bring stakeholders together, coordinate efforts, mobilise resources and raise funding. A national hepatitis $C$ elimination programme should cover all the steps of the continuum of care, including raising awareness, preventative measures, testing, linkage to care and treatment, implementing a monitoring system to gain robust data [24] and adopting a comprehensive public health approach by avoiding a disease-specific, siloed programme [15]. The public health approach aims to strengthen the healthcare system and is an essential tool to achieve the biggest possible advantage for the population.

Some countries, such as Australia [25], Iceland and Switzerland [26], have developed and implemented national strategies. By 2017, 84 of 194 countries, which had endorsed the WHO Global Hepatitis Strategy, had developed a national viral hepatitis plan and 36 countries were in the process of developing plans $[15,27]$. Among the high-income countries, 11 nations are currently on track to meet their elimination goals for hepatitis C by 2030 [28].

Globally, many local initiatives have been started by civil society groups, from service provision to monitoring up to launching national strategies [26,29-31]. All these local initiatives contributed to different levels of the continuum of care with locally adapted goals and structures.

The analysis of the WHO report on the elimination of HCV in 2017 [27] has shown that countries that engage with civil society were more likely to have an elimination plan in place and that most people living with HCV reside in a state with a national strategy.

\section{PREVENTION}

As HCV is a blood-borne virus, prevention plays a crucial part in any HCV infection elimination strategy. Preventative measures like needle and syringe exchange programmes (NSP) and opioid agonist treatment (OAT) are highly effective and well- documented in numerous studies [32]. However, people who inject drugs (PWID), a badly affected group of people, need special attention as they are being subjected to criminalization and discriminatory laws in many countries [33]. They are often forced into illegality and are being excluded from essential services such as primary healthcare or the latest information about testing and treating HCV infection.

The fact that many drugs are illegal leads to high incarceration rates of PWID. In most countries around the world, preventative measures and hepatitis $C$ care in prisons are deplorable. For example, NSPs, which have been proven to be highly effective, are inexistent in most prisons.

In many countries around the globe access to preventive measures for PWID is severly insufficient also outside of prison walls [34]. Therefore, injecting drugs remains a major risk factor for HCV transmission in many regions and countries.

Besides the fact that measures to reduce harm can stop new infections, the treatment itself can act as a prevention measure itself. This aspect is described in detail in the treatment as prevention for hepatitis C (TraP Hep C) study from Iceland, where the HCV RNA prevalence in the population of PWID dropped by over $80 \%$ after treating all HCV infected patients [35]. With this in mind, people who carry a high risk of reinfection should be the first to be treated.

PWID are not the only population group who need special attention to overcome the challenges of infection. The circumstances of people in prisons (or other closed settings), MSM sex workers, indigenous people and migrants require careful consideration when it comes to policy-making. All of these groups are faced with high HCV incidence, a high prevalence of HCV infection, stigma, discrimination, criminalization and difficulties accessing services [36].

The WHO Global Hepatitis Report 2017 [15] notes that, worldwide, $97 \%$ of countries screen blood donations with quality assurance, and unsafe medical injections have decreased from 39\% in 2000 to 5\% in 2010. However, in the Eastern Mediterranean and South-East Asia regions, needles and syringes were frequently reused without being sterilised. Preventative measures within the health system, such as sterile medical equipment and safe blood transfusion practice, are, however, crucial to stop the virus from spreading.

Further prevention measures should focus on safe tattooing and piercing practices $[6,7]$. Special attention is needed for HCV prevention among people in prisons, where unsafe tattooing is very common and HCV prevalence is high [7]. 


\section{DIAGNOSTICS AND TESTING}

Access to affordable and high quality diagnostic services is crucial to scale up testing and treatments. HCV RNA testing is expensive, which often presents an obstacle in low-income and middle-income countries. Antigen tests, on the other hand, are more reasonably priced and can therefore be used as an alternative to confirm or rule out a chronic infection and to measure treatment success.

Hepatitis C can affect anyone. Testing strategies should be adjusted accordingly and adapted to the regional and national epidemiological situation. One way forward is using the riskbased testing approach. However, this is hindered by stigma and taboos surrounding some risk factors, such as the use of illicit substances or certain sexual behaviours. Health professionals do not feel comfortable asking the relevant questions and patients do not disclose the information voluntarily [37]. Birth cohort testing on the other hand [38] is sometimes superseded by current events such as the recent opioid crisis in the United States. It has been repeatedly demonstrated that both of these strategies have missed many cases, and therefore, universal screening is now discussed in several countries. A French study [39] examined different strategies and concluded that universal screening is the most effective of them. It also found the universal approach to be cost-effective if treatment is made available to everybody.

\section{DATA AND MONITORING}

Political stakeholders need reliable data to support a cause and make decisions. Monitoring the elimination goal progress, such as HCV incidence and mortality, is crucial to guide national programmes. In many countries, however, such surveillance tools are missing.

The Global Burden of Disease Study 2017 [16] provides important data for stakeholders around the world. Its findings are vital for research, funding and policy-making. For instance, the GBD study ranks the leading causes of premature death. Several of the causes of death are related to HIV or HCV infection. The report subsumes the different reasons for HIV-related mortality under the infection itself, and as a result, HIV ranks high in the list. As for viral hepatitis, the various causes of death such as liver failure and liver cancer are listed under the resulting disease and not under the infection. Therefore, viral hepatitis does not appear on the list as a potential cause of prema- ture death. This part of the GBD report is an example of how policy-makers can be influenced by scientific publications with potentially severe consequences for those affected.

Worldwide, there is still data missing on the epidemiology of hepatitis $\mathrm{C}$ and on the economic burden caused by direct and indirect costs. More data is needed to increase the pressure to take the necessary action, to successfully promote the elimination of HCV and to monitor the whole process [40].

\section{HEALTHCARE WORKFORCE AND SERVICE DELIVERY}

Not only policy-makers and scientists should possess the skills and knowledge to deal with HCV and its consequences. All healthcare workers, including physicians, should be educated and informed about this treatable infection in order to close the gaps in testing and linkage to care. Capacity building in terms of education within the healthcare system is one step on the road towards HCV elimination. Educating the general public is another move forward, and could in turn encourage policy-makers and stakeholders to initiate further action. Moreover, an informed general population could put pressure on healthcare professionals to keep their knowledge up-to-date.

As DAAs are well-tolerated and the regimen is simple, HCV treatment can take place in primary healthcare facilities, where the patient can be treated effectively by non-specialists [41]. However, in those rare cases where the disease has already progressed or severe comorbiditie are present, specialists and experienced facilitators should be involved. Integrating HCV services into existing care facilities is recommended to increase efficiency and create synergies. PWID can also be treated in primary care services. Ideally, they are included in a comprehensive addiction treatment, including OAT and NSP [31]. Furthermore, $\mathrm{HCV}$ care can be incorporated into existing facilities such as HIV clinics or TB programmes. Nevertheless, it is challenging to incorporate a new health issue in these siloed healthcare programmes [42,43].

\section{GOVERNANCE, FINANCE AND FUNDING}

There is considerable overlap between population groups at risk of acquiring chronic HCV and HIV infections, and both diseases struggle with stigma, which requires a broader approach to reach all those who are infected.

There is insufficient funding for HCV care from global donors, 
such as the Global Fund, the Clinton Foundation and the Bill \& Melinda Gates Foundation, as they still mainly focus on HIV, TB and malaria. These international donors must be made aware of the importance of a comprehensive HCV strategy, as they are such a powerful influence when it comes to setting the agenda of policy-makers.

Whereas HIV has long been in the public eye and on the agenda of policy-makers and stakeholders, HCV remains underdiagnosed and undertreated despite its high morbidity and mortality rates. The more attention a disease gets, the more money for research, intervention programmes and the implementation of strategies is available. Furthermore, policy-makers are influenced by the attention. Switzerland for instance, one of the leading countries in the fight against HIV, has failed to develop a national strategy to tackle HCV [23]. The strategy in place today was initiated entirely by civil organisations and it took several years to get it approved by the government [26]. Switzerland spends about 5 million Swiss franc (CHF; 1 CHF is approximately equivalent to 1.08 US dollars) per year to fight HIV, whereas the federal HCV budget is at about $300000 \mathrm{CHF}$, although HCV kills 5 times more people per year than HIV [44].

When using structures that exist for HIV and TB or making use of addiction treatment services, there is no need to invest in new infrastructures to fight HCV. Investments in workforce skills, education, monitoring and evaluation must be considered. The cost of the medication is a single investment per case, as the treatment cures over $95 \%$ of cases. The medication should be affordable and reasonably priced. In many low-income and middle-income countries, generic DAAs are available for about 100 US dollars per treatment. HCV treatment is cost-effective and still cost-saving even at a much higher price across a range of low-income, middle-income, and high-income countries since it prevents costly medical and economic sequelae [45].

Nevertheless, many countries missed out on cheaper medicines by giving out voluntary licenses for the generic medication. Countries like Australia and Egypt, with strong leadership in the fight against $\mathrm{HCV}$, were able to negotiate with the pharmaceutical companies and lower the price of the medicines considerably.

Based on the WHO Global Health Sector Strategy on Viral Hepatitis [12], a strategic investment framework for the global elimination of hepatitis B and C by 2030 has been developed to support political commitment and identify funding opportunities with a health systems strengthening approach. The investment framework itself is split into three sections. The

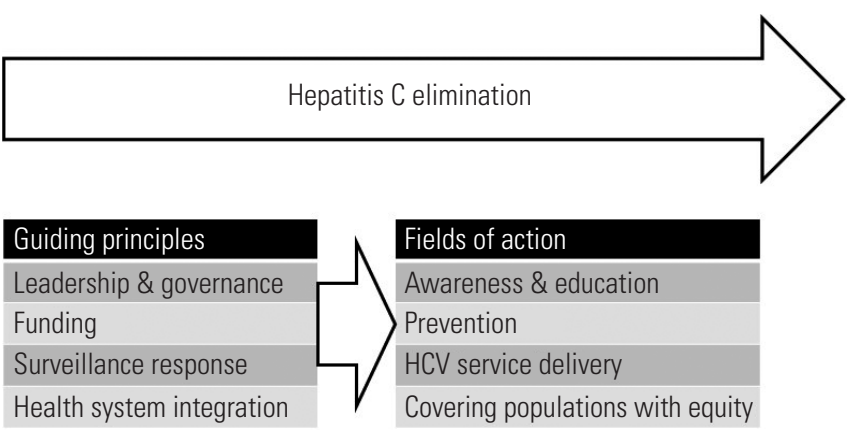

Figure 1. The essential guiding principles and fields of action for a national hepatitis strategy. HCV, hepatitis C virus.

first section presents funding sources and financing mechanisms including the domestic, private and international sector. The second section includes steps to identify key enablers. The last section outlines the economic benefits of a HCV-free society, including direct, indirect and cross-sectional economic benefits [22]. The investment framework highlights how the so-called return on investment influences political decisionmaking. So far, many studies have evaluated the cost-effectiveness of scaling up HCV treatment. These studies have focused on direct costs only [46-48]. Therefore, the return on investment is underestimated as HCV generates high indirect costs, as in decreased workforce and diminished productivity due to illness and premature deaths $[22,49]$. The investment framework is an excellent tool to raise political awareness and build political commitment, by quantifying the benefits not only for public health and the individual, but for the social and economic sector as well (Figure 1).

\section{OVERALL CURRENT SITUATION}

To eliminate HCV as a major public health threat is on the global agenda. It is now time to adjust the national, regional and local agendas accordingly. HCV infection is not an apparent problem in many countries and regions, and therefore often not on the agenda of policy-makers. Treating people successfully is only one essential factor within the healthcare system - awareness and education, advocacy and financing, and access and linkage to testing and care are all necessary to eliminate this 'silent' disease. However, in order to increase the efforts, all stakeholders must be working together and strong political will is required. Also, the benefits of a HCV-free world must be made apparent to encourage all parties involved.

The WHO Global Health Sector Strategy 2016-2021 [12] has 
had an impact and it has made a difference. The 2018 progress report on the elimination of HCV [11] shows achievements in many regions of the world. And yet, only $7 \%$ of the 14 million people who have been diagnosed with HCV have been treated so far [50]. It takes much more than a super-efficient drug to eliminate an infectious disease that causes substantial morbidity and thousands of premature deaths around the world. The different approaches and concepts dealing with the elimination of HCV depend on cultural, economic and personal aspects as well as on the healthcare system itself. Any HCV elimination strategy must fit into the structures and the culture of a country and should pursue a comprehensive public health approach, working with civil society, to achieve elimination by 2030 .

The relevant literature and respective networking groups (e.g., the International Network on Hepatitis in Substance Users) describe many different approaches, projects and positive outcomes. There are also various bottom-up approaches that have achieved considerable success across the continuum of care. In many high-income countries, the successful elimination of HCV lies mainly in the hands of civil society organizations and it is therefore essential to include these informed and experienced groups in the development of adequate policies. Over the past few years, these different groups have accumulated so much expert knowledge that they should be involved in every step of the process of eliminating HCV.

\section{CONCLUSION}

Hepatitis $\mathrm{C}$ and its consequences place a significant burden on public health and national economies worldwide. Even though it is easy to diagnose, the necessary preventative measures are well known and current therapies can cure virtually all patients, there are still significant gaps in care that need to be closed. The disease burden of HCV is often not recognised or underestimated, and there is a lack of coordination between national measures. A great deal of effort is still needed, particularly in the area of social and political awareness, if the global goal of eliminating hepatitis $C$ is to be achieved within the next ten years. A clear political commitment including all stakeholders, strong civil society actors and the relevant support from global donors is an essential prerequisite for a successful national action plan and strategy. The necessary measures to eliminate hepatitis $C$ should be implemented, whenever possible, into existing structures, such as those used in the fight against HIV and TB or to treat people who inject drugs. Only then can hepatitis $C$ and its global disease burden be eliminated efficiently worldwide.

\section{Ethics Statement}

No assessment by an ethics committee was required for this review of the current literature.

\section{CONFLICT OF INTEREST}

The authors have no conflicts of interest associated with the material presented in this paper.

\section{FUNDING}

None.

\section{ACKNOWLEDGEMENTS}

None.

\section{AUTHOR CONTRIBUTIONS}

Conceptualization: NB, PB. Funding acquisition: None. Methodology: NB, PB. Project administration: NB, PB. Visualization: PB. Writing - original draft: NB, PB. Writing - review \& editing: $\mathrm{NB}, \mathrm{PB}$.

\section{ORCID}

Nathalie Brunner https://orcid.org/0000-0002-7559-1269

Philip Bruggmann https://orcid.org/0000-0002-0436-8895

\section{REFERENCES}

1. Lavanchy D. Evolving epidemiology of hepatitis C virus. Clin Microbiol Infect 2011;17(2):107-115.

2. Prati D. Transmission of viral hepatitis by blood and blood derivatives: current risks, past heritage. Dig Liver Dis 2002;34(11): 812-817.

3. Dodd RY, Notari EP 4th, Stramer SL. Current prevalence and incidence of infectious disease markers and estimated window-period risk in the American Red Cross blood donor population. Transfusion 2002;42(8):975-979.

4. Pozzetto B, Memmi M, Garraud O, Roblin X, Berthelot P. Health care-associated hepatitis $C$ virus infection. World J Gastroen- 
terol 2014;20(46):17265-17278.

5. Nijmeijer BM, Koopsen J, Schinkel J, Prins M, Geijtenbeek TB. Sexually transmitted hepatitis $\mathrm{C}$ virus infections: current trends, and recent advances in understanding the spread in men who have sex with men. J Int AIDS Soc 2019;22(S6):e25348.

6. Yang S, Wang D, Zhang Y, Yu C, Ren J, Xu K, et al. Transmission of hepatitis $B$ and $C$ virus infection through body piercing: a systematic review and meta-analysis. Medicine (Baltimore) 2015;94(47):e1893.

7. Jafari S, Copes R, Baharlou S, Etminan M, Buxton J. Tattooing and the risk of transmission of hepatitis $\mathrm{C}$ : a systematic review and meta-analysis. Int J Infect Dis 2010;14(11):e928-e940.

8. Grebely J, Applegate TL, Cunningham P, Feld JJ. Hepatitis C point-of-care diagnostics: in search of a single visit diagnosis. Expert Rev Mol Diagn 2017;17(12):1109-1115.

9. Falade-Nwulia O, Suarez-Cuervo C, Nelson DR, Fried MW, Segal JB, Sulkowski MS. Oral direct-acting agent therapy for hepatitis $C$ virus infection: a systematic review. Ann Intern Med 2017; 166(9):637-648.

10. World Health Organization. Accelerating access to hepatitis $C$ diagnostics and treatment: overcoming barriers in low- and middle-income countries. Global progress report 2020; 2021 [cited 2021 Jul 20]. Available from: https://www.who.int/publications/i/item/9789240019003.

11. World Health Organization. Progress report on access to hepatitis $\mathrm{C}$ treatment: focus on overcoming barriers in low- and middle-income countries; 2018 [cited 2021 Mar 1]. Available from: https://www.who.int/publications/i/item/progress-report-on-access-to-hepatitis-c-treatment.

12. World Health Organization. Global health sector strategy on viral hepatitis 2016-2021. Towards ending viral hepatitis; 2016 [cited 2021 Mar 1]. Available from: https://apps.who.int/iris/ handle/10665/246177.

13. World Health Organization. Sixty-seventh World Health Assembly (WHA67.6): hepatitis; 2014 [cited 2021 Mar 1]. Available from: https://www.worldhepatitisalliance.org/sites/default/files/resources/documents/WHA67.6.pdf.

14. Polaris Observatory HCV Collaborators. Global prevalence and genotype distribution of hepatitis $C$ virus infection in 2015: a modelling study. Lancet Gastroenterol Hepatol 2017;2(3):161-176.

15. World Health Organization. Global hepatitis report, 2017 [cited 2021 Mar 1]. Available from: https://www.who.int/publications/i/item/global-hepatitis-report-2017.

16. GBD 2017 Causes of Death Collaborators. Global, regional, and national age-sex-specific mortality for 282 causes of death in
195 countries and territories, 1980-2017: a systematic analysis for the Global Burden of Disease Study 2017. Lancet 2018; 392(10159):1736-1788.

17. Younossi Z, Park H, Henry L, Adeyemi A, Stepanova M. Extrahepatic manifestations of hepatitis C: a meta-analysis of prevalence, quality of life, and economic burden. Gastroenterology 2016;150(7):1599-1608.

18. Lee KK, Stelzle D, Bing R, Anwar M, Strachan F, Bashir S, et al. Global burden of atherosclerotic cardiovascular disease in people with hepatitis $C$ virus infection: a systematic review, meta-analysis, and modelling study. Lancet Gastroenterol Hepatol 2019;4(10):794-804.

19. Cacoub P, Buggisch P, Carrión JA, Cooke GS, Zignego AL, Beckerman $\mathrm{R}$, et al. Direct medical costs associated with the extrahepatic manifestations of hepatitis $\mathrm{C}$ infection in Europe. J Viral Hepat 2018;25(7):811-817.

20. Younossi ZM, Stepanova M, Henry L, Younossi I, Weinstein A Nader $F$, et al. Association of work productivity with clinical and patient-reported factors in patients infected with hepatitis C virus. J Viral Hepat 2016;23(8):623-630.

21. Lindgren $P$, Löfvendahl S, Brådvik G, Weiland O. Reduced work absenteeism in patients with hepatitis $C$ treated with secondgeneration direct-acting antivirals. J Viral Hepat 2021;28(1): 142-146.

22. Pedrana A, Howell J, Scott N, Schroeder S, Kuschel C, Lazarus $J V$, et al. Global hepatitis C elimination: an investment framework. Lancet Gastroenterol Hepatol 2020;5(10):927-939.

23. Kind J, Maeschli B, Bruggmann P. In the shadow of HIV: the Cinderella hepatitis C. Suchtmed 2019;21(3):103-110 (German).

24. Negro F, Weis N, Lazaru J. EASL policy statement hepatitis $C$ elimination; 2019 [cited $2021 \mathrm{Jul}$ 10]. Available from: https:// easl.eu/wp-content/uploads/2019/07/EASL-Policy-Statement-on-Hepatitis-C-Elimination_June2019.pdf.

25. Australian Government Department of Health. Fifth national hepatitis C strategy 2018-2022; 2018 [cited 2021 Jul 1]. Available from: https://www1.health.gov.au/internet/main/publishing.nsf/Content/ohp-bbvs-1/\$File/Hep-C-Fifth-Nat-Strategy-2018-22.pdf.

26. Blindenbacher R, Maeschli B, Bruggmann P. The Swiss hepatitis strategy as a model for facing future health policy challenges. Health Policy 2019;123(7):681-687.

27. Smith $S$, Harmanci $H$, Hutin $Y$, Hess $S$, Bulterys $M$, Peck R, et al. Global progress on the elimination of viral hepatitis as a major public health threat: an analysis of WHO Member State responses 2017. JHEP Rep 2019;1(2):81-89. 
28. Razavi H, Sanchez Gonzalez Y, Yuen C, Cornberg M. Global timing of hepatitis $C$ virus elimination in high-income countries. Liver Int 2020;40(3):522-529.

29. Schatz $E$. The importance of civil society involvement in eliminating hepatitis C. EMJ Hepatol 2017;5(1):48-49.

30. Maticic M, Pirnat Z, Leicht A, Zimmermann R, Windelinck T, Jauffret-Roustide $M$, et al. The civil society monitoring of hepatitis $C$ response related to the WHO 2030 elimination goals in 35 European countries. Harm Reduct J 2020;17(1):89.

31. Scherz N, Bruggmann P, Brunner N. Direct-acting antiviral therapy for hepatitis $C$ infection among people receiving opioid agonist treatment or heroin assisted treatment. Int J Drug Policy 2018;62:74-77.

32. Martin NK, Hickman M, Hutchinson SJ, Goldberg DJ, Vickerman P. Combination interventions to prevent HCV transmission among people who inject drugs: modeling the impact of antiviral treatment, needle and syringe programs, and opiate substitution therapy. Clin Infect Dis 2013;57(Suppl 2):S39-S45.

33. Global Commission on Drug Policy. The negative impact of the war on drugs on public health: the hidden hepatitis C epidemic; 2013 [cited 2021 Jul 1]. Available from: https://www. drugsandalcohol.ie/28474/1/GCDP_HepatitisC_2013_EN.pdf.

34. United Nations Office on Drugs and Crime. World drug report 2017: 29.5 million people globally suffer from drug use disorders, opioids the most harmful [cited 2021 Mar 1]. Available from: https://www.unodc.org/unodc/en/frontpage/2017/June/ world-drug-report-2017_-29-5-million-people-globally-sufferfrom-drug-use-disorders--opioids-the-most-harmful.html.

35. Olafsson S, Tyrfingsson T, Runarsdottir V, Bergmann OM, Hansdottir I, Björnsson ES, et al. Treatment as prevention for hepatitis C (TraP Hep C) - a nationwide elimination programme in Iceland using direct-acting antiviral agents. J Intern Med 2018; 283(5):500-507.

36. World Health Organization. Guidelines for the care and treatment of persons diagnosed with chronic hepatitis $C$ virus infection; 2018 [cited 2021 Mar 1]. Available from: https://www. who.int/publications/i/item/9789241550345.

37. Jhaveri R, Broder T, Bhattacharya D, Peters MG, Kim AY, Jonas MM. Universal screening of pregnant women for hepatitis $C$ : the time is now. Clin Infect Dis 2018;67(10):1493-1497.

38. Armstrong GL, Wasley A, Simard EP, McQuillan GM, Kuhnert WL, Alter MJ. The prevalence of hepatitis $C$ virus infection in the United States, 1999 through 2002. Ann Intern Med 2006; 144(10):705-714.

39. Deuffic-Burban S, Huneau A, Verleene A, Brouard C, Pillonel J,
Le Strat Y, et al. Assessing the cost-effectiveness of hepatitis $C$ screening strategies in France. J Hepatol 2018;69(4):785-792.

40. World Health Organization. Monitoring and evaluation for viral hepatitis B and C: recommended indicators and framework; 2016 [cited 2021 Mar 1]. Available from: https://apps.who.int/ iris/handle/10665/204790.

41. Kattakuzhy S, Gross C, Emmanuel B, Teferi G, Jenkins V, Silk R, et al. Expansion of treatment for hepatitis $C$ virus infection by task shifting to community-based nonspecialist providers: a nonrandomized clinical trial. Ann Intern Med 2017;167(5): 311-318.

42. Umutesi G, Shumbusho F, Kateera F, Serumondo J, Kabahizi J, Musabeyezu E, et al. Rwanda launches a 5-year national hepatitis C elimination plan: a landmark in sub-Saharan Africa. J Hepatol 2019;70(6):1043-1045.

43. Devi S. Ukrainian health authorities adopt hepatitis $C$ project. Lancet 2020;396(10246):228.

44. Müller D. Interpellation 19.3042: federal funding for the fight against viral hepatitis; 2019 [cited 2021 Jul 15]. Available from: https://www.parlament.ch/de/ratsbetrieb/suche-curia-vista/ geschaeft?Affairld=20193042 (German).

45. Douglass CH, Pedrana A, Lazarus JV, 't Hoen EF, Hammad R, Leite RB, et al. Pathways to ensure universal and affordable access to hepatitis C treatment. BMC Med 2018;16(1):175.

46. Chhatwal J, He T, Lopez-Olivo MA. Systematic review of modelling approaches for the cost effectiveness of hepatitis $C$ treatment with direct-acting antivirals. Pharmacoeconomics 2016;34(6):551-567.

47. Heffernan A, Cooke GS, Nayagam S, Thursz M, Hallett TB. Scaling up prevention and treatment towards the elimination of hepatitis C: a global mathematical model. Lancet 2019;393 (10178):1319-1329.

48. Tordrup D, Hutin Y, Stenberg K, Lauer JA, Hutton DW, Toy M, et al. Additional resource needs for viral hepatitis elimination through universal health coverage: projections in 67 low-income and middle-income countries, 2016-30. Lancet Glob Health 2019;7(9):e1180-e1188.

49. Scott N, Kuschel C, Pedrana A, Schroeder S, Howell J, Thompson $A$, et al. A model of the economic benefits of global hepatitis $C$ elimination: an investment case. Lancet Gastroenterol Hepatol 2020;5(10):940-947.

50. Ward JW, Hinman AR. What Is needed to eliminate hepatitis B virus and hepatitis $C$ virus as global health threats. Gastroenterology 2019;156(2):297-310. 